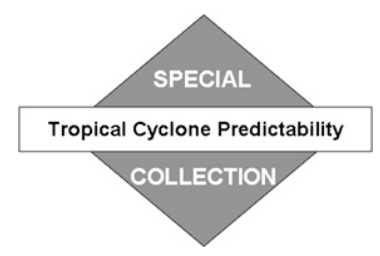

\title{
An Observing System Experiment for Typhoon Conson (2004) Using a Singular Vector Method and DOTSTAR Data
}

\author{
MUNEHIKO YAMAGUCHI AND TAKESHI IRIGUCHI \\ Japan Meteorological Agency, Tokyo, Japan \\ TETSUO NAKAZAWA \\ Meteorological Research Institute, Tsukuba, Japan \\ CHUN-CHIEH Wu \\ National Taiwan University, Taipei, Taiwan
}

(Manuscript received 13 June 2008, in final form 2 March 2009)

\begin{abstract}
An Observing System Experiment (OSE) has been performed to investigate the effectiveness of dropwindsonde observations and a sensitivity analysis technique on a typhoon track forecast. Using dropwindsonde observations for Typhoon Conson at 1200 UTC 8 June 2004, which are derived from Dropwindsonde Observation for Typhoon Surveillance near the Taiwan Region (DOTSTAR), four numerical experiments are conducted, which are different only in terms of the number of dropwindsonde observations used in a data assimilation system: (i) no observation is assimilated; (ii) all observations are assimilated; (iii) observations within a sensitive region as revealed by a singular vector method at the Japan Meteorological Agency (JMA) are assimilated; and (iv) observations outside the sensitive region are assimilated. In the comparison of the four track forecasts, Conson's northeastward movement is expressed in the second and third simulations while in the first and fourth experiments Conson stays at almost the same position as its initial position. Through the OSE, it is found that DOTSTAR observations had a positive impact on the track forecast for Conson, and that observations within the sensitive region are enough to predict the northeastward movement of Conson, indicating that the JMA singular vector method would be useful for the sampling strategy of targeted observations like DOTSTAR.
\end{abstract}

\section{Introduction}

During the last few decades there have been significant advances in tropical cyclone (TC) track forecasts along with the remarkable progress of numerical weather prediction (NWP) systems. The verification of TC track forecasts by operational global models has been conducted under the framework of the Working Group on Numerical Experimentation (WGNE) since 1991 (World Climate Research Programme 1993). For the western North Pacific, for example, it was shown that the annual average position error of 4-day forecasts in $2005(301 \mathrm{~km})$, which are the consensus of the European Centre for

Corresponding author address: Munehiko Yamaguchi, 1-3-4 Ote-machi, Chiyoda-ku, Tokyo 100-8122, Japan.

E-mail: munehiko.yamaguchi@gmail.com
Medium-Range Weather Forecasts (ECMWF), the Japan Meteorological Agency (JMA), and the Met Office (UKMO), is about the same as that of the 2-day forecasts in $1991(282 \mathrm{~km})$, indicating the success in obtaining a 2-day lead time over the past $15 \mathrm{yr}$ (Komori et al. 2007). However, we all know that forecast uncertainty is one key unavoidable aspect of weather forecasting due to the chaotic nature of the atmosphere as well as the imperfection of NWP systems. Tropical cyclone track forecasts are no exception. Consequently, sometimes an almost perfect forecast may only contain position error of less than $50 \mathrm{~km}$ in a 3-day forecast. However, sometimes the 3-day forecast error can be over $1000 \mathrm{~km}$. For this reason, the Ensemble Prediction System (EPS) has been attracting attention because it is expected to provide uncertainty information inherent to each forecast event (e.g., Puri et al. 2001; Yamaguchi et al. 2009). 
Meanwhile, there was an attempt to reduce TC track forecast uncertainty itself under The Observing System Research and Predictability Experiment (THORPEX) Pacific Asian Regional Campaign (T-PARC) in 2008. One of the main goals of T-PARC is to lessen forecast uncertainty of TCs, which may cause severe weather events on a time scale of 1 day to 2 weeks. For this purpose, dropwindsonde (Hock and Franklin 1999) observations by aircraft were deployed in an effort to understand detailed three-dimensional TC structures and TC surrounding environments, and to produce more accurate initial fields for NWP models with the supplementary observation data. In T-PARC, adaptive sampling techniques (Buizza and Montani 1999; Majumdar et al. 2006; Wu et al. 2009b) were used, aimed at maximizing the impact of the observations on NWP.

Prior to the above field experiment, we investigated the impact of additional observations on TC track forecasts using JMA's data assimilation and global forecasting system, and the feasibility of adopting a singular vector (SV) method (Palmer et al. 1998) developed at JMA as a sensitivity analysis technique. As for the additional observations, we used Dropwindsonde Observations for Typhoon Surveillance near the Taiwan Region (DOTSTAR) data for Typhoon Conson observed at 1200 UTC 8 June 2004.

Similar surveys have been conducted by Aberson (2003, 2002), Aberson and Franklin (1999), and Burpee et al. (1996), focusing on hurricanes in the Atlantic and the eastern and central Pacific. According to these surveys, it has been found that initial conditions that assimilate all observational data led to statistically better hurricane track forecasts as compared to initial conditions without targeted observations. These studies also demonstrated that adaptive sampling techniques would be useful for the decision-making process on dropwindsonde deployments because TC track forecasts, which include observations just within sensitive regions, statistically have better performance with respect to those that includes all observations. Following the previous studies, this study aims to evaluate the following two issues:

1) Impact of selected DOTSTAR observations on the track forecast of Conson at 1200 UTC 8 June 2004;

2) Feasibility of the JMA SV method as a sensitivity analysis technique.

For these purposes, two sets of Observing System Experiments (OSEs) are performed. In the first OSE (OSE-1), two initial conditions are created, which are different only in terms of the number of observations used through the data assimilation: one is made without DOTSTAR data; and the other is made with all dropwindsonde data. In the second OSE (OSE-2), just like
OSE-1, two initial conditions are created, which are also different only in terms of observations used during the data assimilation: one is made by assimilating DOTSTAR data within a sensitive region as identified by the JMA SV method, and the other is made using the data outside the sensitive region. We could answer the first question through OSE-1 and the second question through OSE-2.

Section 2 describes DOTSTAR data for Conson and the synopsis of the typhoon. Sections 3 and 4 describe the experimental designs and the results of OSE- 1 and OSE-2, respectively. Section 5 examines the scientific issues on the role of the additional observation data and on what the sensitive region identified by the JMA SV method represents. The conclusions are presented in section 6 .

\section{Brief overview of DOTSTAR and Typhoon Conson}

\section{a. The DOTSTAR project and its data for Typhoon Conson}

DOTSTAR is a field experiment conducted by the National Taiwan University and the Central Weather Bureau of Taiwan, along with the National Oceanic and Atmospheric Administration (NOAA) since 2002 (Wu et al. 2005). DOTSTAR has collected adaptive airborne dropwindsonde observations for typhoons that may affect the Taiwan area, aiming at the improvement of typhoon track forecasts with its additional observation data. The observations are available through the Global Telecommunication System (GTS) in real time, and JMA has used them for its data assimilation since 2004. Studies have shown that the DOTSTAR data have on average improved the 6-72-h track forecasts from operational global models of JMA, the National Centers for Environmental Prediction (NCEP), and the Fleet Numerical Meteorological and Oceanographic Center (FNMOC) by about $20 \%$ for 10 cases studied in 2004 (Wu et al. 2007a; Chou and Wu 2008).

The Astra SPX jet, which cruises at about $750 \mathrm{~km} \mathrm{~h}^{-1}$ at up to about $14 \mathrm{~km}$ with a maximum flight range of about $6.5 \mathrm{~h}$, is used in this field experiment. Dropwindsondes are released in and around a TC every 150-200 km close to the resolution of the traditional rawinsonde network. To maximize the possible improvement of numerical forecasts with the limited aircraft resources, targeted observation techniques are adopted. Three sensitivity analysis products were first taken into consideration to determine the observation strategy: the deep-layer mean (DLM) wind variance using NCEP EPS (Aberson 2003), the ensemble transform Kalman filter (EnTKF) based on the 40-member NCEP EPS (Majumdar et al. 2002) and SVs by Navy Operational Global Atmospheric Prediction System (NOGAPS; 

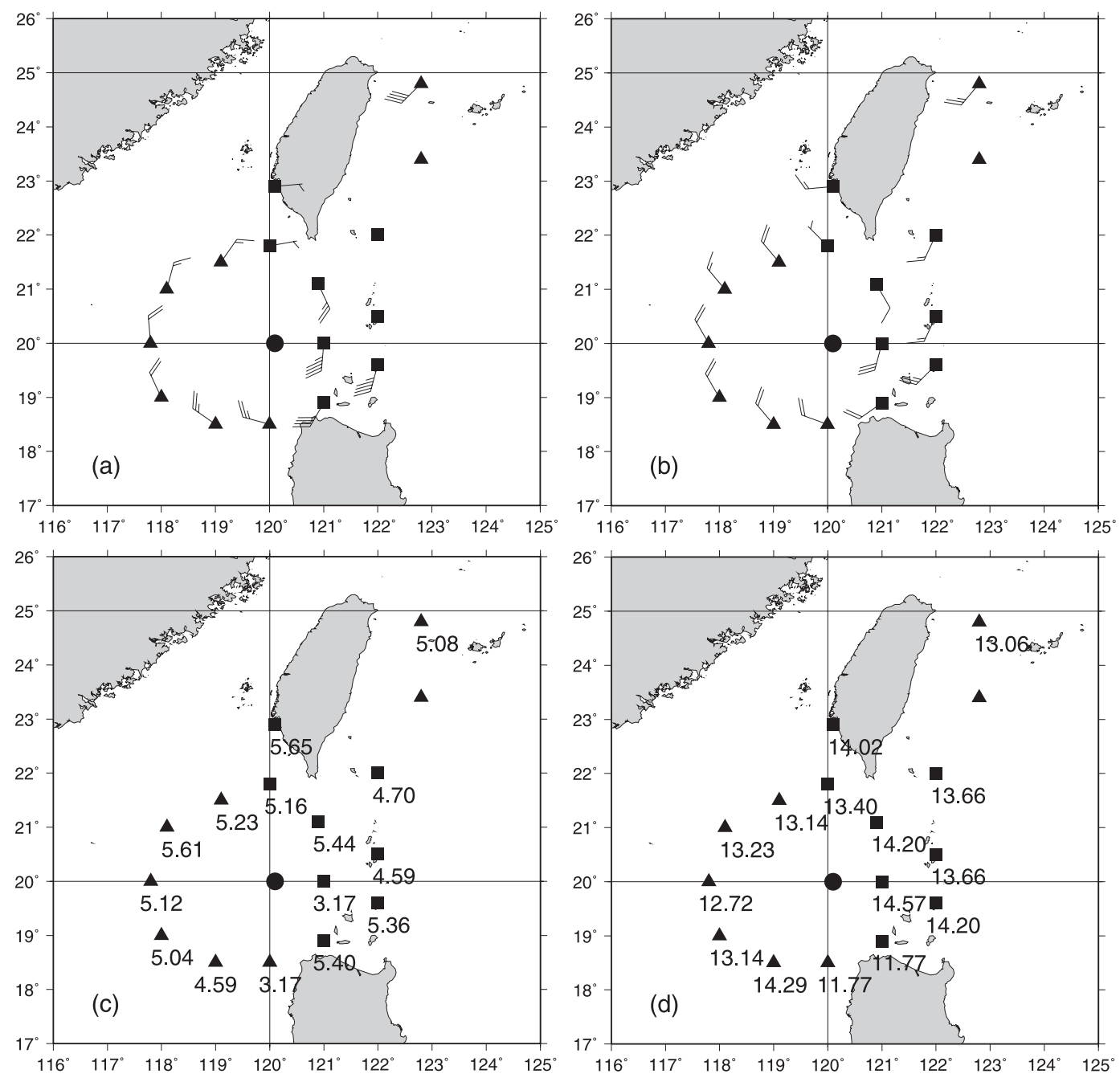

FIG. 1. DOTSTAR observations at 1200 UTC 8 Jun 2004 (square and triangle points): (a) 500-hPa wind, (b) $250-\mathrm{hPa}$ wind, (c) $500-\mathrm{hPa}$ specific humidity, and (d) $850-\mathrm{hPa}$ specific humidity. In (a) and (b), a long barb represents $5 \mathrm{~m} \mathrm{~s}^{-1}$ and a short barb represents $2.5 \mathrm{~m} \mathrm{~s}^{-1}$. In (c) and (d), the observation values $\left(\mathrm{g} \mathrm{kg}^{-1}\right)$ are indicated under each observation point. No line or value is shown at points of missing data. The black dot represents the analyzed central position of Conson.

Rosmond 1997; Gelaro et al. 2002; Peng and Reynolds 2006; Reynolds et al. 2009). Along with the progress in DOTSTAR, the fourth method, the adjoint-derived sensitivity steering vector (ADSSV), has been developed at the National Taiwan University and is currently used for the decision making of dropwindsonde deployments (Wu et al. 2007b, 2009a,b).

Sixteen dropwindsondes were released around Conson between 1000 and 1400 UTC 8 June 2004. The squares and triangles in Figs. 1a-d show the location of dropwindsonde observations. As of June 2004, sensitivity analysis guidance mentioned above had not been fully employed yet. Most dropwindsondes were therefore deployed every $150-200 \mathrm{~km}$ in a circular pattern with its center at Conson's central position, and several dropwindsondes were deployed during the ferry flight. The observation data include wind speed, wind direction, temperature, and relative humidity below $195 \mathrm{hPa}$. As an example, wind observations at 500 and $250 \mathrm{hPa}$ are shown in Figs. 1a,b (a long barb for $5 \mathrm{~m} \mathrm{~s}^{-1}$ and a short barb for $2.5 \mathrm{~m} \mathrm{~s}^{-1}$ ), and specific humidity at 500 and $850 \mathrm{hPa}$ are shown in Figs. 1c,d with observation values $\left(\mathrm{g} \mathrm{kg}^{-1}\right)$ indicated beneath each observation point.

\section{b. Synopsis of Typhoon Conson}

The best track and intensity of Conson analyzed by the Regional Specialized Meteorological Center (RSMC) Tokyo-Typhoon Center are shown in Fig. 2. Conson formed as a tropical depression in the South China Sea at 1800 UTC 4 June 2004. It moved eastward, 

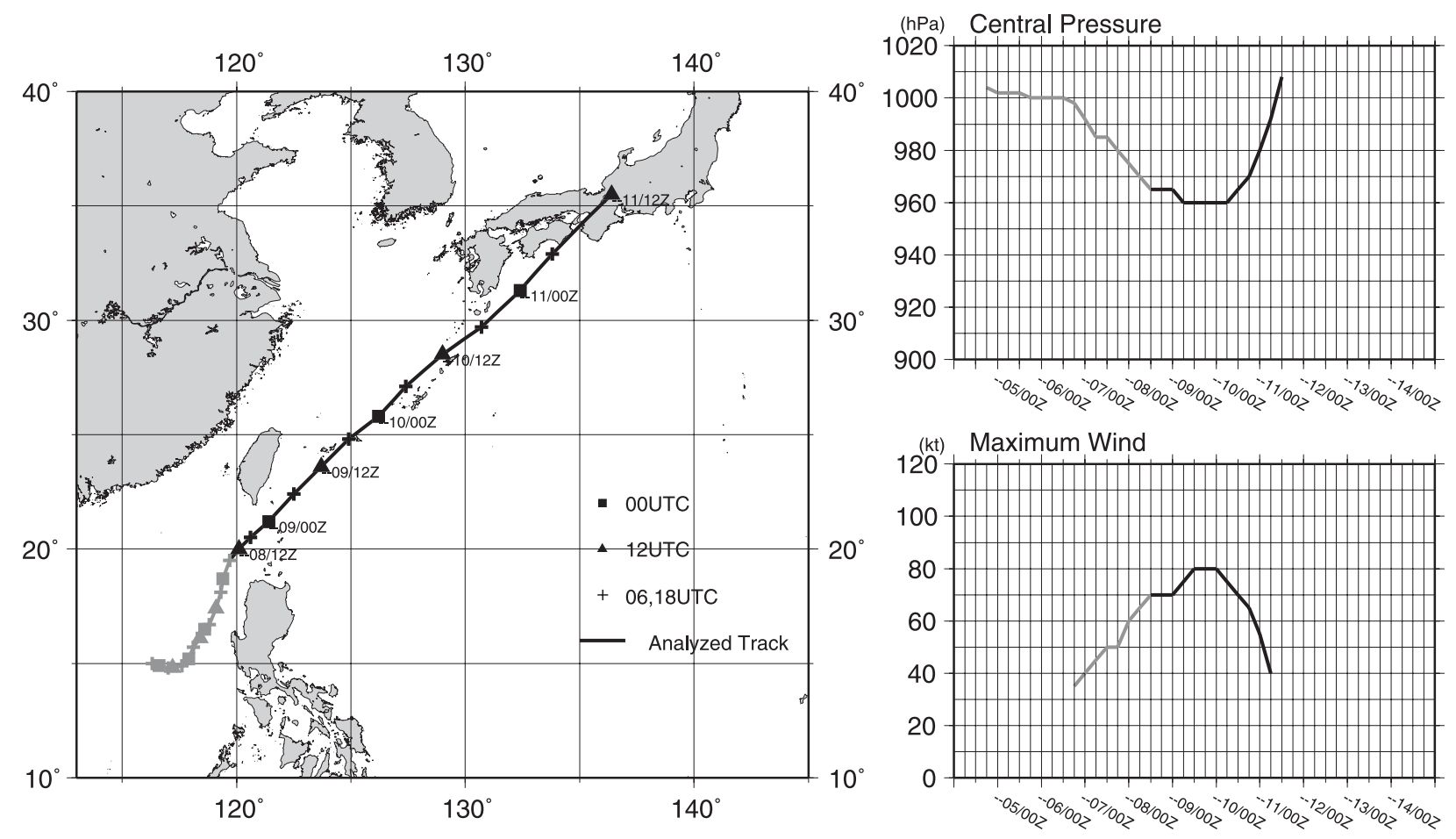

FIG. 2. Analyzed track and intensity of Conson. (left) The analyzed track of Conson from 1800 UTC 4 Jun 2004 (time of genesis) to 1200 UTC 11 Jun 2004. From the genesis time to the observation time, 1200 UTC 8 Jun 2004, the line is shown in gray color and after that it is shown in black color. The analyzed intensity: (top right) central pressure ( $\mathrm{hPa}$ ) and (bottom right) maximum wind (kt).

then north-northeastward and developed into a tropical storm off the west coast of the Luson Island at 1800 UTC 6 June. After that, Conson changed its course toward the northeast and reached typhoon intensity at 0600 UTC 8 June. Still moving in the same direction, Conson reached the peak intensity with the maximum sustained wind of $80 \mathrm{kt}$ at 1200 UTC 9 June. It made landfall over Shikoku at 0700 UTC 11 June with tropical storm strength (RSMC Tokyo-Typhoon Center 2004). As 1 of the 11 typhoons landing on Japan in 2004, Conson caused a torrential rainfall of $40 \mathrm{~mm} \mathrm{~h}^{-1}$ in Kochi and $85 \mathrm{~mm} \mathrm{~h}^{-1}$ in Tanegashima.

To understand the synoptic environment at 1200 UTC 8 June 2004, the analysis field of wind and geopotential height at 500 and $250 \mathrm{hPa}$ are shown in Figs. 3a,b. These are the results of JMA four-dimensional variational data assimilation system (4DVAR; Kadowaki 2005; JMA 2007; the analysis fields shown in Figs. 3a,b were produced without DOTSTAR data). Figure 3a shows that Conson was located at the west edge of the Pacific high, and Fig. $3 b$ shows that it was located at just south of the westerly jet with its axis lying on the west side against Conson's central position: the westerly wind with a little southerly flow was present just north of Conson. As these figures show, Conson was in a confluent area induced by the westerly jet and the southerly flow at the west edge of the Pacific high. These are the remarkable characteristics of the synoptic environment around Conson at 1200 UTC 8 June when the DOTSTAR observation was conducted.

\section{OSE-1: Impact of dropwindsonde observations on Conson's track prediction}

\section{a. Experimental description}

OSE-1 is performed to investigate the impact of additional observations on Conson's track prediction. For this purpose, JMA's operational NWP system for global forecasting as of February 2005 is used: the 4DVAR system for data assimilations (the resolutions of the inner and outer model are T63L40 and TL319L40, respectively) and the global spectral model (TL319L40) for numerical integrations. Two initial conditions are produced, which are different only in terms of the number of observations used in the data assimilation: one is made without DOTSTAR data and the other is made using all of the data (hereafter, the experiment in which no DOTSTAR data is assimilated is referred to as NODROP, and the other with all DOTSTAR data assimilated is referred to as ALLDROP).

\section{b. Results of OSE-1}

The results of OSE-1 are shown in Fig. 4 and Table 1. The thin (thick) solid line is a track forecast of NODROP 


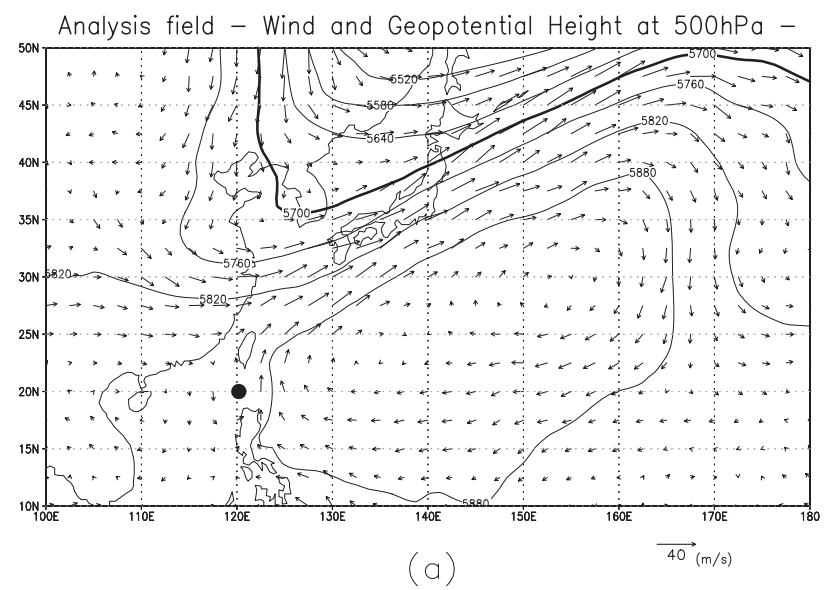

(a)

FIG. 3. Synoptic environment around Conson at 1200 UTC 8 Jun 2004. Wind and geopotential height (m) at (a) 500 and (b) $250 \mathrm{hPa}$. Wind vector scale $\left(\mathrm{m} \mathrm{s}^{-1}\right)$ at the bottom right on each figure and geopotential height is given with line. The black dot represents the analyzed central position of Conson.

(ALLDROP). Comparison of these two tracks indicates that ALLDROP can capture Conson's northeastward movement despite of a strong slow bias. On the other hand, Conson heads toward north and finally disappears just after making landfall on Taiwan in NODROP. Verification against the best track by RSMC Tokyo-Typhoon Center shows that the position errors of NODROP and ALLDROP are 410 and $181 \mathrm{~km}$ for the 24-h forecast, respectively. This result demonstrates that DOTSTAR data show a very positive impact on improving Conson's track prediction at 1200 UTC 8 June 2004.

\section{c. Differences of the initial conditions between NODROP and ALLDROP}

In this section we focus on the differences of the initial conditions used in NODROP and ALLDROP in order to understand how the inclusion of the drop-

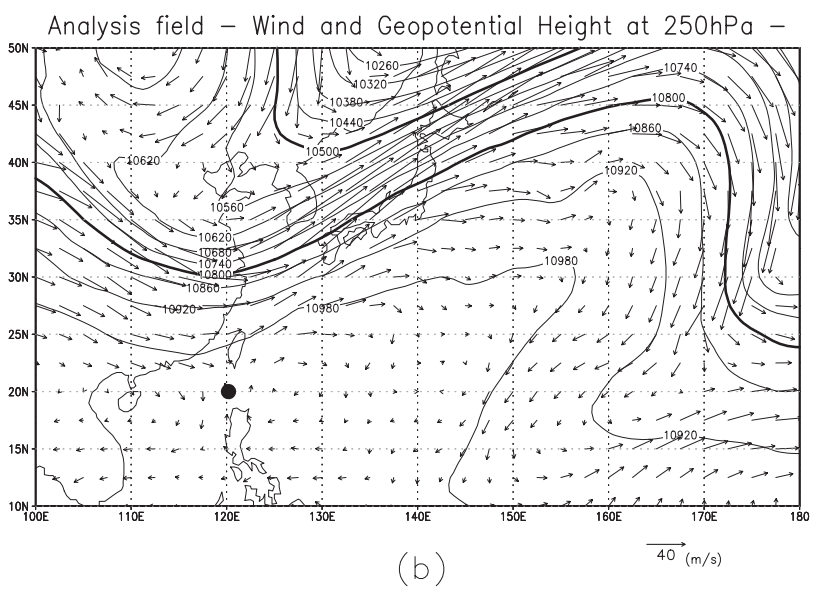




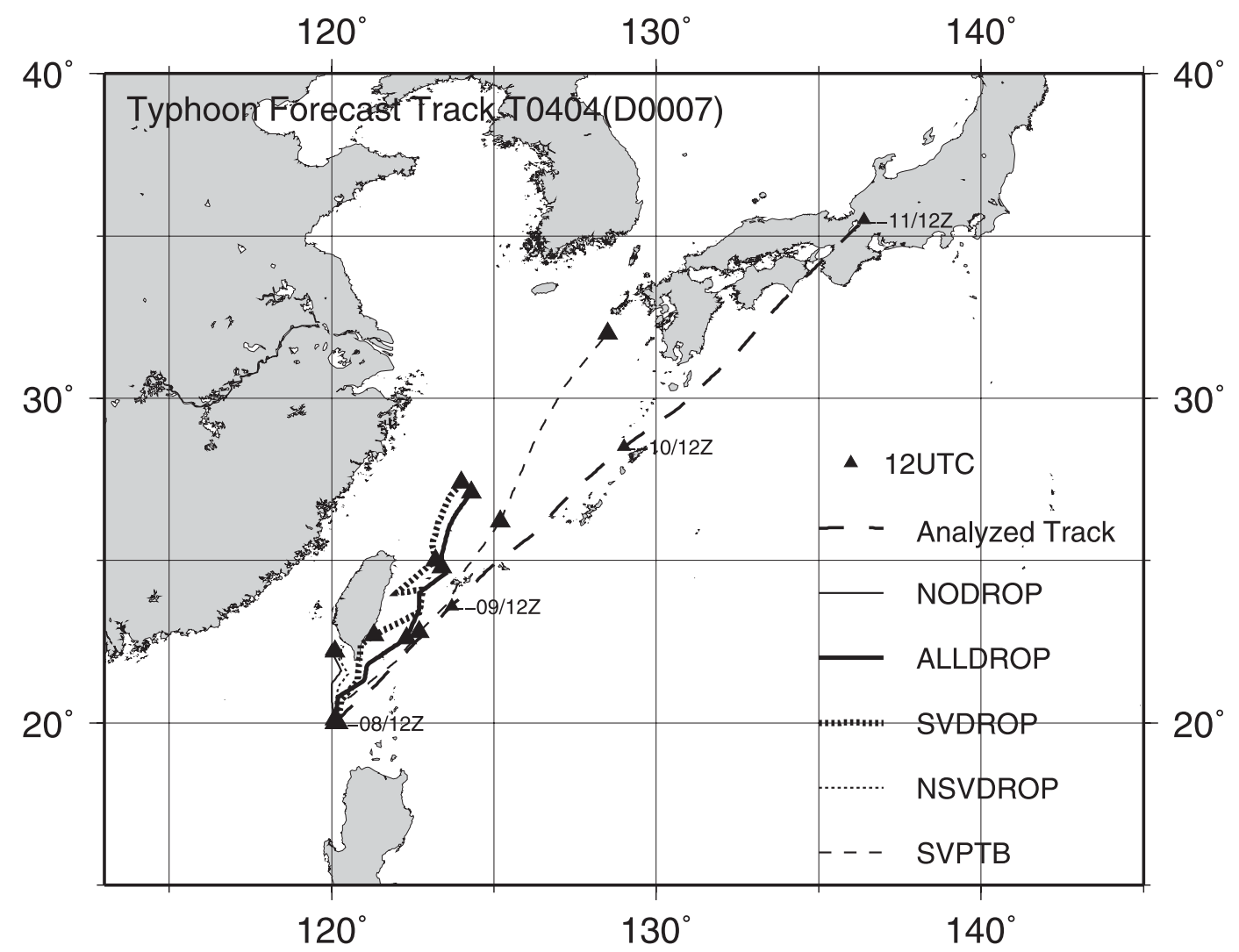

FIG. 4. Results of OSE-1, OSE-2, and SVPTB. The thick (thin) solid line is track prediction from ALLDROP (NODROP), the thick (thin) dot line is for SVDROP (NSVDROP), and the short dashed line is for SVPTB. The long dashed line is the analyzed track of Conson. The triangles on each track are plotted every $24 \mathrm{~h}$.

Figures $6 \mathrm{a}-\mathrm{e}$ show the horizontal distributions of the analysis increments in ALLDROP. The vertically accumulated total energy of the analysis increments is given in Fig. 6a, its vorticity and specific humidity components are given in Figs. $6 \mathrm{~b}, \mathrm{c}$, and wind vectors and isotachs at 250 and $500 \mathrm{hPa}$ are given in Figs. $6 \mathrm{~d}$,e, respectively. As shown in Figs. 6b,d,e, the vorticity increments consist of three vortical structures: 1 ) a cyclonic circulation at the northeast region against Conson's central position, 2) an anticyclonic circulation at the opposite side, and 3) another anticyclonic circulation about $500 \mathrm{~km}$ east of Conson's central position. It should be noted that the peak points of the vorticity increments are not necessarily consistent with the area where the wind increments have large amplitudes.

Figures 7a-d show the initial fields of NODROP and ALLDROP regarding vorticity (shaded) and streamline (arrow) at 250 (left) and $500 \mathrm{hPa}$ (right). There are two major differences at the 250 -hPa level; one is that the location of maximum vorticity in ALLDROP is shifted to the best-track position of Conson, likely owing to the use of all dropwindsonde information surrounding Conson, and the other is the steering flow associated with the west edge of the Pacific high. The steering flow in NODROP is from south to north, which is almost same as the direction of the forecast track as shown in Fig. 4. For ALLDROP, on the other hand, the flow is from southwest to northeast, which is consistent with the direction of the motion of Conson simulated in ALLDROP. This flow change is the most prominent at $250 \mathrm{hPa}$, but it can be also seen from about 200 to $500 \mathrm{hPa}$ though the impact becomes less distinct away from the 250-hPa level.

Figures $8 \mathrm{a}-\mathrm{f}$ show the initial fields of NODROP and ALLDROP and the differences between them, regarding specific humidity at 500 (left) and $850 \mathrm{hPa}$ (right), where analysis increments are relatively large.

TABLE 1. Position errors (km) of 24-, 48-, and 72-h forecasts at each experiment.

\begin{tabular}{lccc}
\hline \hline & $24 \mathrm{~h}$ & $48 \mathrm{~h}$ & $72 \mathrm{~h}$ \\
\hline NODROP & 410 & - & - \\
ALLDROP & 181 & 692 & 1479 \\
SVDROP & 265 & 692 & 1479 \\
NSVDROP & 400 & - & - \\
SVPTB & 135 & 454 & 827 \\
\hline
\end{tabular}




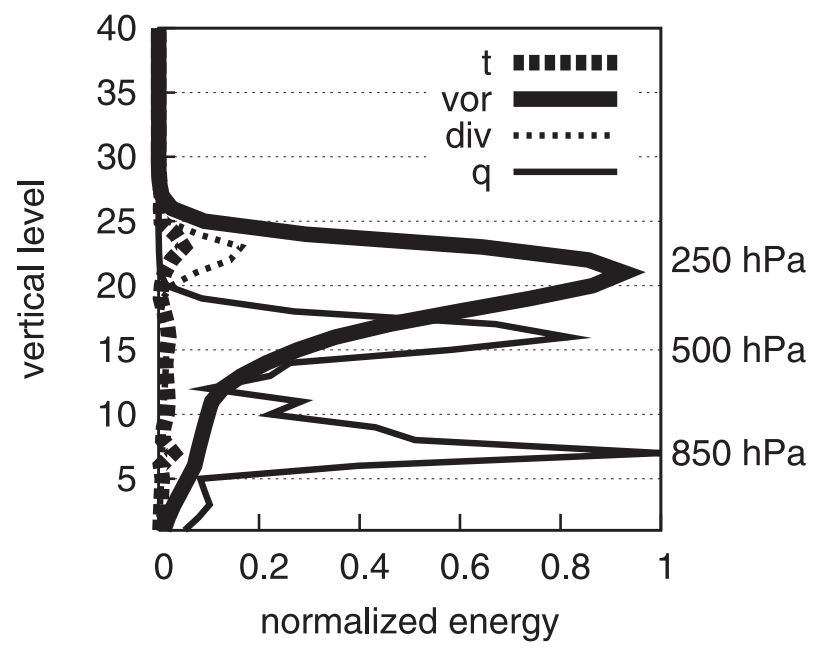

FIG. 5. Analysis increments resulting from assimilating all observations in ALLDROP. They are represented as a form of the vertical distribution of each component of the total energy. Vertical level 7 almost corresponds to $850 \mathrm{hPa}$, level 15 corresponds to $500 \mathrm{hPa}$, and level 22 corresponds to $250 \mathrm{hPa}$. Amplitudes are normalized by the peak value of all variables and all model levels.

Compared with observations shown in Figs. 1c,d, it is revealed that the initial field of NODROP has less moisture content almost all around the typhoon at both the middle and lower model levels. By assimilating the dropwindsonde observations, however, these inadequate expressions are improved and the initial expression of the moisture field in ALLDROP becomes close to the observations from the DOTSTAR soundings.

\section{OSE-2: Feasibility of adopting JMA's singular vector method as a sensitivity analysis technique}

\section{a. Experimental description}

Another OSE, OSE-2, is performed to investigate the feasibility of adopting JMA's SV method as a sensitivity analysis technique. Just like OSE-1, two initial conditions are produced, which are different only in terms of observations used in the data assimilation: one is made with DOTSTAR data within a sensitive region as revealed by the SV method (SVDROP) and the other is made using the data outside the sensitive region (NSVDROP). The other configurations such as the 4DVAR data assimilation system and the NWP model (global spectral model with TL319L40) are exactly the same as those used in OSE-1.

\section{b. Singular vector method at JMA}

Under the assumption that a perturbation grows linearly, a SV with a large singular value represents a fast- growing perturbation (Lorenz 1965). Consider a growth rate of a perturbation $\mathbf{x}$ as shown in (2):

$$
\frac{\left\|\mathbf{x}\left(t=t_{a}\right)\right\|}{\left\|\mathbf{x}\left(t=t_{0}\right)\right\|} \quad \mathbf{x} \in R^{n}
$$

where $\mathbf{x}\left(t=t_{0}\right)$ is a perturbation at a base time $t_{0}, \mathbf{x}\left(t=t_{a}\right)$ is one at an optimization time $t_{a}\left(t_{a}>t_{0}\right)$, and $\|\cdot\| \mathrm{de}-$ notes the norm associated with the Euclidean inner product. The growth rate of a perturbation given by Eq. (2) changes into Eq. (3), using a tangent forward propagator $\mathbf{M}$ :

$\frac{\left\|\mathbf{x}\left(t=t_{a}\right)\right\|}{\left\|\mathbf{x}\left(t=t_{0}\right)\right\|}=\sqrt{\frac{\left[\mathbf{T M x}\left(t=t_{0}\right), \mathbf{E}_{f} \mathbf{T M x}\left(t=t_{0}\right)\right]}{\left[\mathbf{x}\left(t=t_{0}\right), \mathbf{E}_{i} \mathbf{x}\left(t=t_{0}\right)\right]}}$,

where $\mathbf{E}_{i}$ and $\mathbf{E}_{f}$ are norm operators at $t_{0}$ and $t_{a}$, respectively. The local projection operator $\mathbf{T}$ makes a vector to zero outside a prescribed domain, which enables to calculate perturbations with maximum amplitude at $t_{a}$ over the targeted area. Here (,) denotes the Eulerian inner product. The growth rate equation still changes to Eqs. (4) and (5) from Eq. (3), using $\hat{\mathbf{x}}=\mathbf{E}_{i}^{1 / 2} \mathbf{x}\left(t=t_{0}\right), \mathbf{A}=\mathbf{E}_{f}^{1 / 2} \mathbf{T M E}_{i}^{-1 / 2}$ and adjoint matrix represented by the superscript $*$ :

$$
\begin{aligned}
\frac{\left\|\mathbf{x}\left(t=t_{a}\right)\right\|}{\left\|\mathbf{x}\left(t=t_{0}\right)\right\|} & =\sqrt{\frac{\left[\hat{\mathbf{x}},\left(\mathbf{E}_{f}^{1 / 2} \mathbf{T M E}_{i}^{-1 / 2}\right) * \mathbf{E}_{f}^{1 / 2} \mathbf{T M E}_{i}^{-1 / 2} \hat{\mathbf{x}}\right]}{(\hat{\mathbf{x}}, \hat{\mathbf{x}})}} \\
& =\sqrt{\frac{(\hat{\mathbf{x}}, \mathbf{A} * \mathbf{A} \hat{\mathbf{x}})}{(\hat{\mathbf{x}}, \hat{\mathbf{x}})}}
\end{aligned}
$$

Equation (5) represents that SVs, or forward SVs of matrix $\mathbf{A}$, grow up about a given trajectory with their growth rates of the corresponding singular values. Therefore the first SV, which has the largest singular value, maximizes the ratio in Eq. (2) and the second SV gives the fastest-growing perturbation following the first SV, and so on. These SVs are the solutions of the eigenvalue problem shown in Eq. (6):

$$
\mathbf{A} * \mathbf{A} \hat{\mathbf{x}}=\lambda \hat{\mathbf{x}} \quad(\lambda: \text { eigenvalue })
$$

In this study, $\mathbf{M}$ and $\mathbf{M}^{*}$ are the tangent-linear and adjoint models used for the 4DVAR data assimilation system at JMA, which has been in operation since February 2005 (Kadowaki 2005). The resolutions are T63L40. They consist of dynamics based on Eulerian integrations and physical processes containing representations of vertical diffusion, gravity wave drag, large-scale 

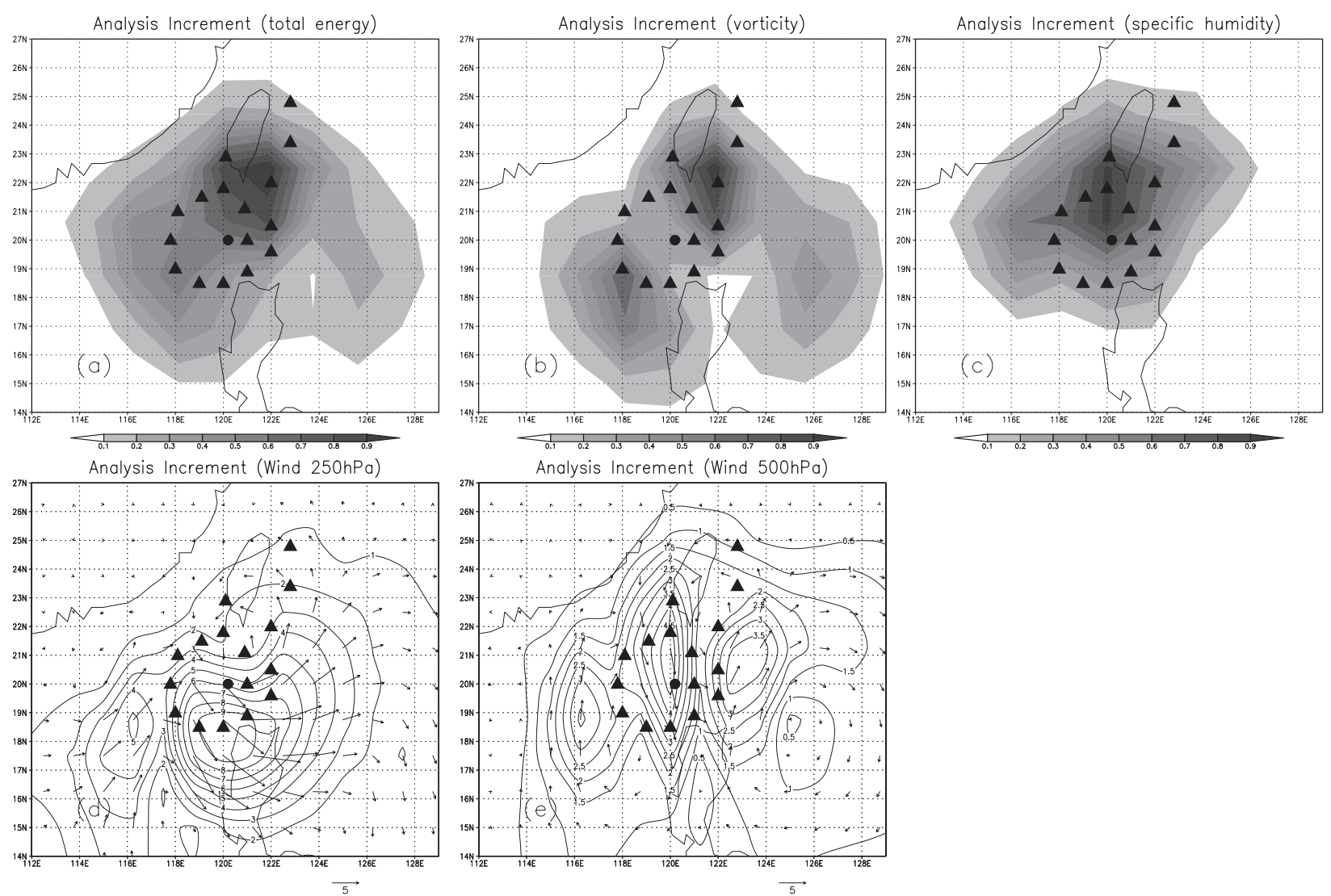

FIG. 6. Horizontal distributions of the analysis increments in ALLDROP: (a) the vertically accumulated total energy of the analysis increments; (b) its vorticity; and (c) specific humidity component; and wind vectors and isotachs ( $\mathrm{m} \mathrm{s}^{-1}$ ) at (d) 250 and (e) $500 \mathrm{hPa}$, (the vector scale is shown at the bottom right on each figure). In (a),(b), and (c), amplitudes are normalized by the maximum value of the whole filed. The black dot and rectangles represent the analyzed central position of Conson and the observation points, respectively.

condensation, longwave radiation, and deep cumulus convection. Two kinds of SVs can be calculated: one is dry SVs and the other is moist SVs. The dry SVs, which are expected to identify the dynamically most unstable mode of the atmosphere like the baroclinic mode, are obtained using the simplified physical process that only includes vertical diffusion. For the moist SVs that are computed using the full physical process, they can capture the uncertainty in the area such as a tropical region or a TC surrounding where moist processes are crucial (Barkmeijer et al. 2001; Puri et al. 2001; Kim and Jung 2009). Both SVs are computed applying an iterative Lanczos procedure (e.g., Strang 1986) to the linear propagator $\mathbf{M}$ instead of solving Eq. (6) directly.

\section{c. Singular vector calculation for Typhoon Conson}

A moist SV calculation is performed targeting Conson. The initial time is 1200 UTC 8 June 2004, when DOTSTAR conducted its airborne observation. The optimization time interval $t_{a}-t_{0}$ is $24 \mathrm{~h}$ : the optimization time is 1200 UTC 9 June 2004. The targeted region is a rectangle, $5^{\circ}$ latitude $\times 10^{\circ}$ longitude with its center at Conson's analyzed position at the evaluation time, $23.3^{\circ} \mathrm{N}, 123.8^{\circ} \mathrm{E}$. The initial condition for the SV calculation is produced by interpolating an analysis field with TL319L40 resolution, which does not include any DOTSTAR data.

Following the results of OSE-1, we eliminate the effects of temperature and divergence from the total energy at the initial time when carrying out the SV calculation. In addition, the influence of specific humidity is limited below model level 20 (at about the 300-hPa level). In the final norm, only the effect of vorticity under model level 15 (at about the 500-hPa level) is evaluated to focus on the representation of a TC. Figures 9a,b show the vertically accumulated energy of the first moist $\mathrm{SV}$ at the initial and evaluation time, respectively. Amplitudes in both figures are normalized by the maximum value in the field. It is found that the large amplitudes extend from north to southeast about 200 to $500 \mathrm{~km}$ away from Conson's central position in the initial SV, and that there exists a TC-like cyclonic structure whose center is close 

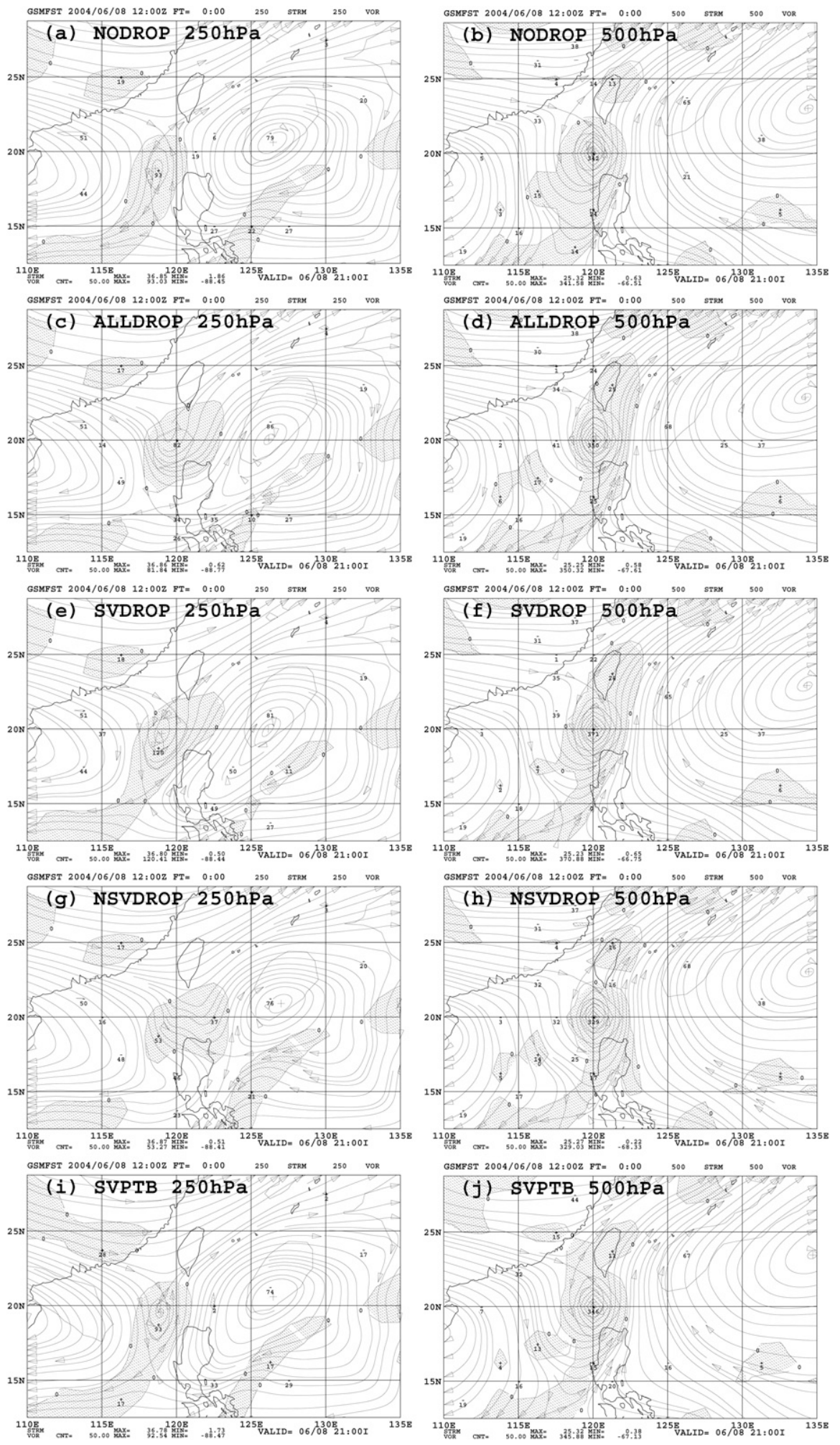

FIG. 7. Initial fields of NODROP, ALLDROP, SVDROP, NSVDROP, and SVPTB, regarding vorticity (shaded, $10^{-6} \mathrm{~s}^{-1}$ ) and streamline (arrow) at (left) 250 and (right) $500 \mathrm{hPa}$. 

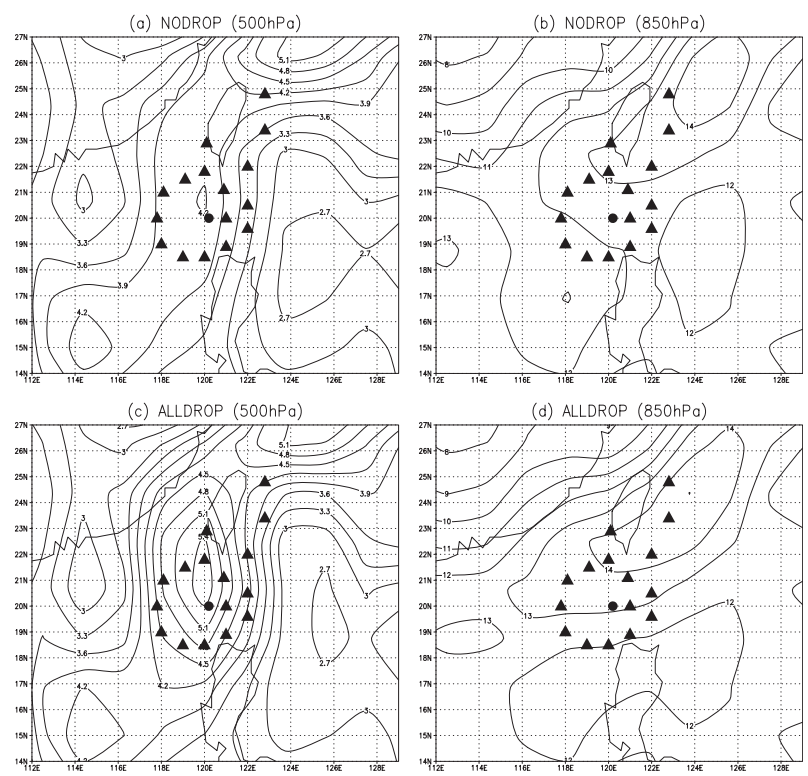

(e) ALLDROP - NODROP (500hPa)
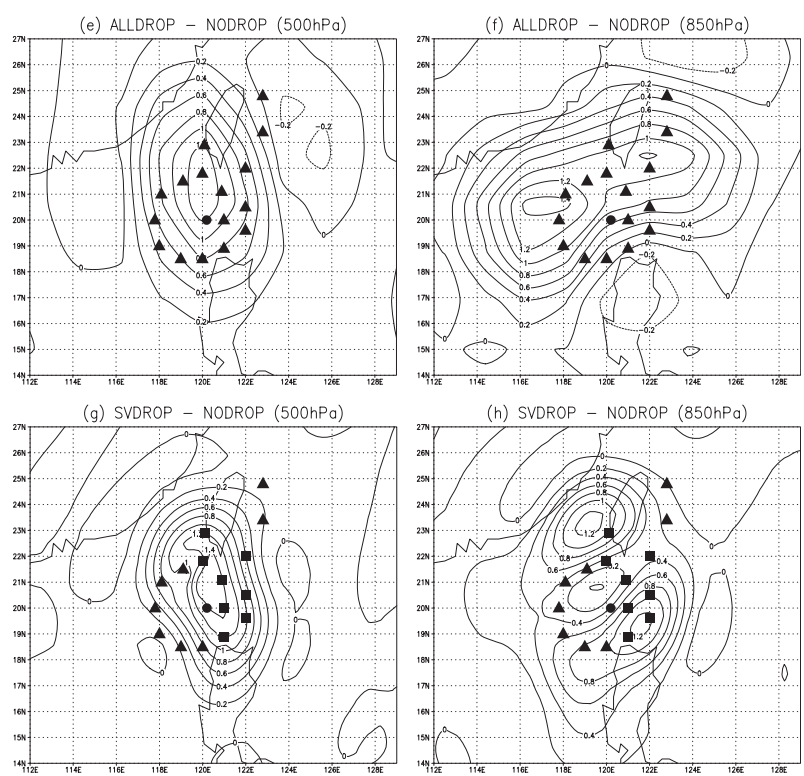

(i) NSVDROP - NODROP $(500 \mathrm{hPa})$
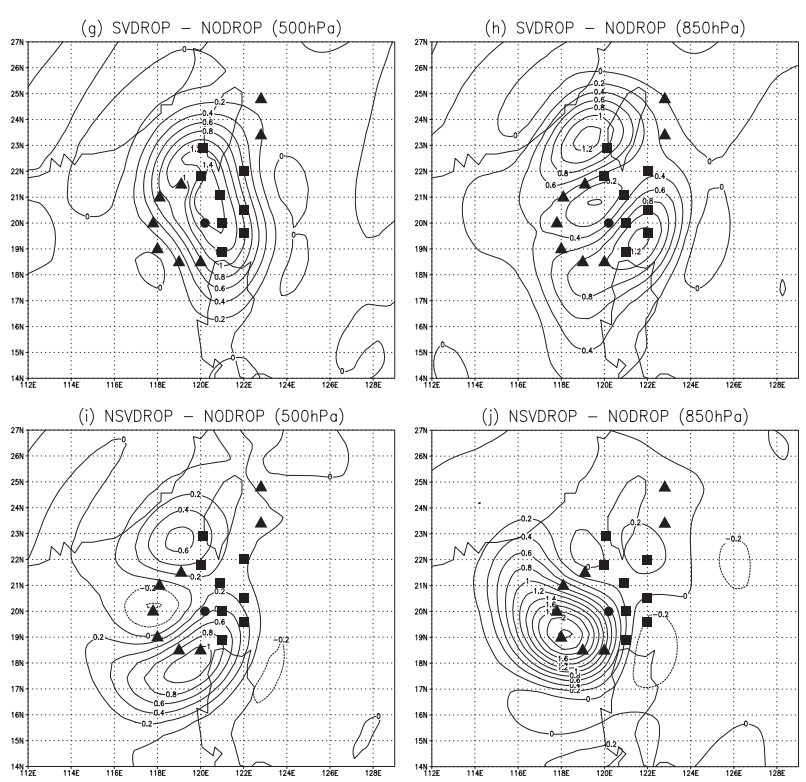

FIG. 8. Initial fields of NODROP and ALLDROP and differences from NODROP, regarding specific humidity $\left(\mathrm{g} \mathrm{kg}^{-1}\right)$ at (left) 500 and (right) $850 \mathrm{hPa}$. (a)-(f) The triangles represent observations assimilated in ALLDROP. (g)-(j) The squares and triangles represent observations assimilated in SVDROP and in NSVDROP, respectively. The black dot represents the analyzed central position of Conson. to the analyzed position of Conson at the evaluation time in the final SV. The sensitive region is related to synoptic features such as the western edge of the Pacific high, the westerly jet just north of Conson and a convective area in the outer bands southeast of the typhoon (see section 5a for more details).

When the initial condition of SVDROP is produced, eight observation points, half the number of the total observation points, are selected in the order corresponding to the amount of the total energy, or sensitivity. As a result, the squares in Fig. 1 are selected for SVDROP while the other half of the data (triangles in Fig. 1) are selected when producing the initial condition of NSVDROP.

\section{d. Results of OSE-2}

The results of OSE-2 are shown in Fig. 4 and Table 1. The thick (thin) dot line is the track forecast of SVDROP (NSVDROP). In the comparison of these two tracks, SVDROP shows Conson's northeastward movement similar to ALLDROP. On the other hand, the typhoon dissipates near Taiwan in NSVDROP just like NODROP. This result demonstrates that in this particular case, DOTSTAR data within the sensitive region is all it takes to capture Conson's movement toward the northeast, and that the sensitivity analysis guidance using the JMA SV method appears effective for targeted observations of typhoons such as in DOTSTAR.

\section{e. Characteristics of the initial conditions of SVDROP and NSVDROP}

Figures $7 \mathrm{e}-\mathrm{h}$ show the initial fields of SVDROP and NSVDROP, regarding the vorticity (shaded) and streamline (arrow) fields at 250 (left) and $500 \mathrm{hPa}$ (right). Not assimilating observations in a circular pattern fully around Conson, the initial field of SVDROP at $250 \mathrm{hPa}$ does not produce the vorticity shift as shown in ALLDROP. However, SVDROP has the same characteristic as ALLDROP in resolving the critical southwesterly wind as seen in the southeastern side of Conson. Just like in ALLDROP, the flow change is the most prominent at $250 \mathrm{hPa}$, and the influence becomes weaker in proportion to the distance from the $250-\mathrm{hPa}$ level. On the contrary, the southerly wind is dominant at the corresponding region in NSVDROP, which fails to realize Conson's northeastward movement. We believe this is the essential difference in the model's initial condition leading to the completely dissimilar two groups of track forecasts in ALLDROP/SVDROP and NODROP/ NSVDROP.

Figures $8 \mathrm{~g}-\mathrm{j}$ show the differences of the initial fields between SVDROP and NODROP, and the differences 

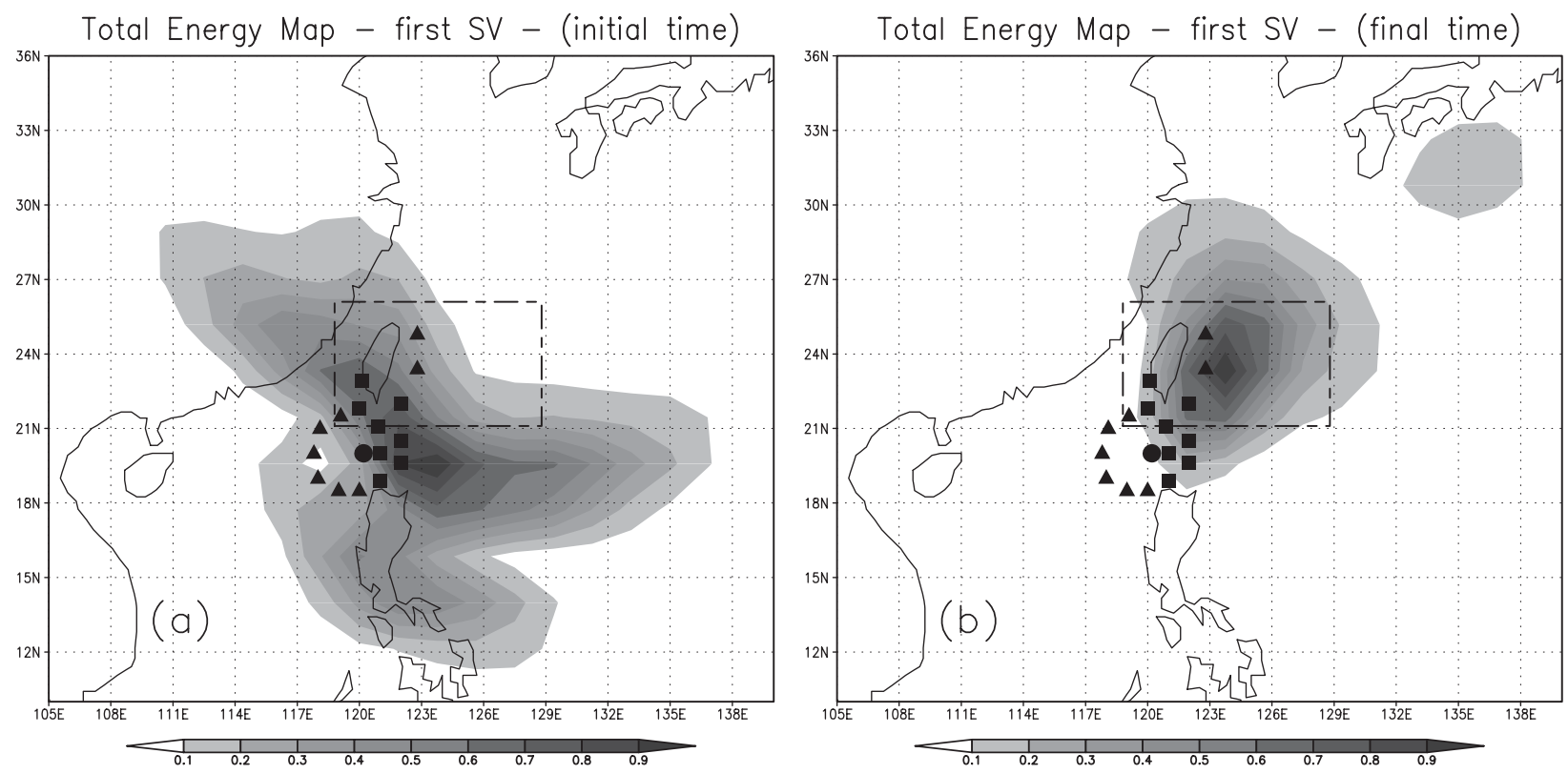

FIG. 9. Vertically accumulated energy of the first moist SV at (a) the initial time and (b) the evaluation time. Amplitudes in both figures are normalized by the maximum value in each field. The dash rectangle shows the targeted area for the SV calculation. Symbols as in Fig. 8 .

between NSVDROP and NODROP, regarding specific humidity at 500 (left) and $850 \mathrm{hPa}$ (right). In response to the observations assimilated, there exists the enhancement of specific humidity from the southeast to the north area of Conson from the lower to middle levels in the initial field of SVDROP, which is almost the same characteristic as ALLDROP as seen in Figs. 8e,f. On the other hand, the increased specific humidity is limited from northwest to south in NSVDROP.

Through OSE-1 and OSE-2, it is found that the common features of the initial conditions in both ALLDROP and SVDROP, where Conson's track forecasts are improved, are the northeastward steering flow from the middle to the upper troposphere, which is associated with the west edge of the Pacific high, and the enhancement of specific humidity from the southeast to north of Conson from the lower to middle troposphere. Although it would be difficult to identify exactly what element and which area may have contributed to the improvement of the track forecast, our understanding of the steering flow (Wu et al. 2003, 2004) suggests that the analysis increments causing the modification of the wind field should have played an important role in Conson's northeastward movement prediction. In addition, the area of specific humidity increments includes the convective area in the outer bands of the typhoon, indicating that the improvement of outer structure representation might also play a role in the track change. In fact, as will be shown in section $5 \mathrm{a}$, the specific humidity component of the first $\mathrm{SV}$ is also found to be important.

\section{Discussion}

\section{a. SV structure}

To more closely examine the effectiveness of the JMA SV method as a sensitivity analysis technique, this section focuses on what the SV shown in Fig. 9a reflects and how well it explains the analysis increments in ALLDROP and SVDROP, where Conson's track forecasts are improved.

Before going into the details about the structure of the SV, the validity of the linear growth assumption of the SV calculation is investigated by the study of the similarity index proposed by Buizza (1994). The similarity index is a value of inner product of two vectors, and therefore, by considering an evolved SV and a nonlinearly growing SV as the two vectors, the similarity of those two vectors can be examined. Here, the evolved SV is the result of integrating the first SV up to the evaluation time with the T63L40 tangent-linear model, and the nonlinearly growing SV is the result of operating a norm operator at the evaluation time, $\mathbf{E}_{f}$, to the differences between the nonperturbed run and the perturbed run at the evaluation time, where both runs are based on the T63L40 nonlinear model, and the first $\mathrm{SV}$ is used as an initial perturbation in the perturbed run. The amplitudes of the initial perturbation are determined in the same way as the Typhoon Ensemble Prediction System (TEPS) at JMA (Yamaguchi et al. 2009) so that the maximum value of the zonal or meridional wind perturbations is equal to $6 \mathrm{~m} \mathrm{~s}^{-1}$ (i.e., approximately 


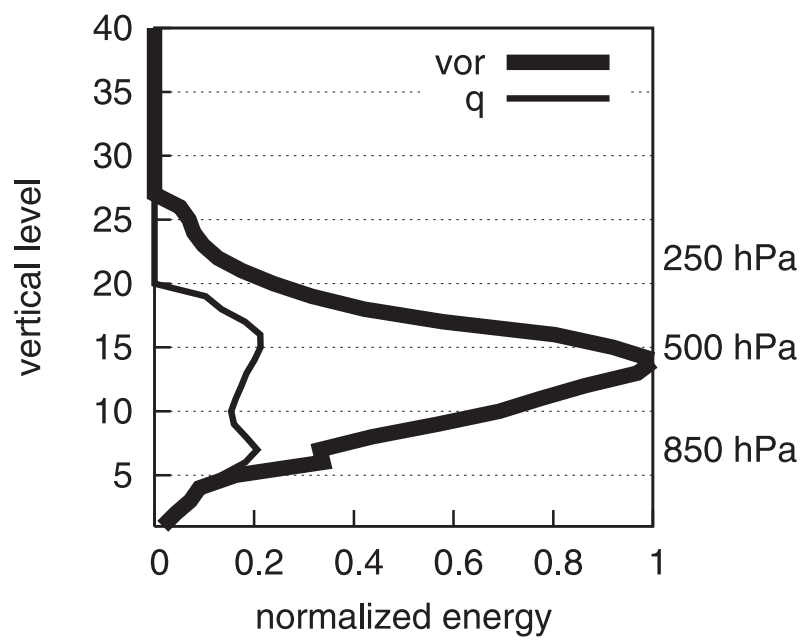

FIG. 10. Vertical energy distribution of the first moist SV at the initial time. The thick line represents the vorticity component of energy and the thin line does the specific humidity component. Vertical level 7 almost corresponds to $850 \mathrm{hPa}$, level 15 corresponds to $500 \mathrm{hPa}$, and level 22 corresponds to $250 \mathrm{hPa}$. Amplitudes are normalized by the peak value of the two variables and all model levels.

same amplitude as analysis increments shown in Fig. 6e). The similarity index of the above setting is 0.95 . This high similarity index denotes that the linear growth assumption is well maintained during the evaluation time interval, and that the initial SV is expected to grow in a nonlinear model as is the case with a linear model up to the evaluation time.

Figure 10 shows the vertical energy distribution of the initial SV. The initial SV is mainly explained by the vorticity component with the highest energy at model level 14 (at about the 540-hPa level). Figure 11a shows the vertically accumulated vorticity component of en- ergy of the initial SV, and Figs. 11b,c show the wind vectors and isotachs at 250 and $500 \mathrm{hPa}$, where the $\mathrm{SV}$ is amplified in the same way as TEPS. As shown in Figs. $11 \mathrm{a}-\mathrm{c}$, the vorticity perturbation consists of two vortical structures: 1) a large cyclonic circulation extending from the northwest to east relative to Conson's central position, and 2) an anticyclonic circulation to the south of Conson. Regarding the wind field, the south to east side of Conson has an eastward component just like in ALLDROP (Figs. 6d,e). When the analysis increments of vorticity in ALLDROP (Fig. 6b) are compared to the SV vorticity structure, it is shown that both have high similarity. In actuality, the $\mathrm{SV}$ is being used as an initial perturbation and added to the initial field of NODROP (the amplitudes are determined in the same way as TEPS), and the southerly winds at the eastern side of Conson have changed to the southwesterly wind, which is the very characteristic in ALLDROP and SVDROP (Figs. 7i,j). This result confirms that the SV succeeds in capturing a sensitive region that may have a large impact on forecasting as seen in the differences between ALLDROP/SVDROP and NODROP/ NSVDROP.

Figure 12a shows the vertically accumulated specific humidity component of energy of the initial SV. The area with large amplitudes is seen in the southeast region about $300 \mathrm{~km}$ away from the central position, where outer bands exist. Figures $12 b, c$ show the vertically accumulated specific humidity component of energy of the initial and final SVs, which are calculated under the condition that only the effect of specific humidity is considered in a formulation of an initial norm (in the final norm, as in the SV calculation mentioned at section $3 c$, only the effect of vorticity under model level 15 is considered just to focus on the representation of a TC).
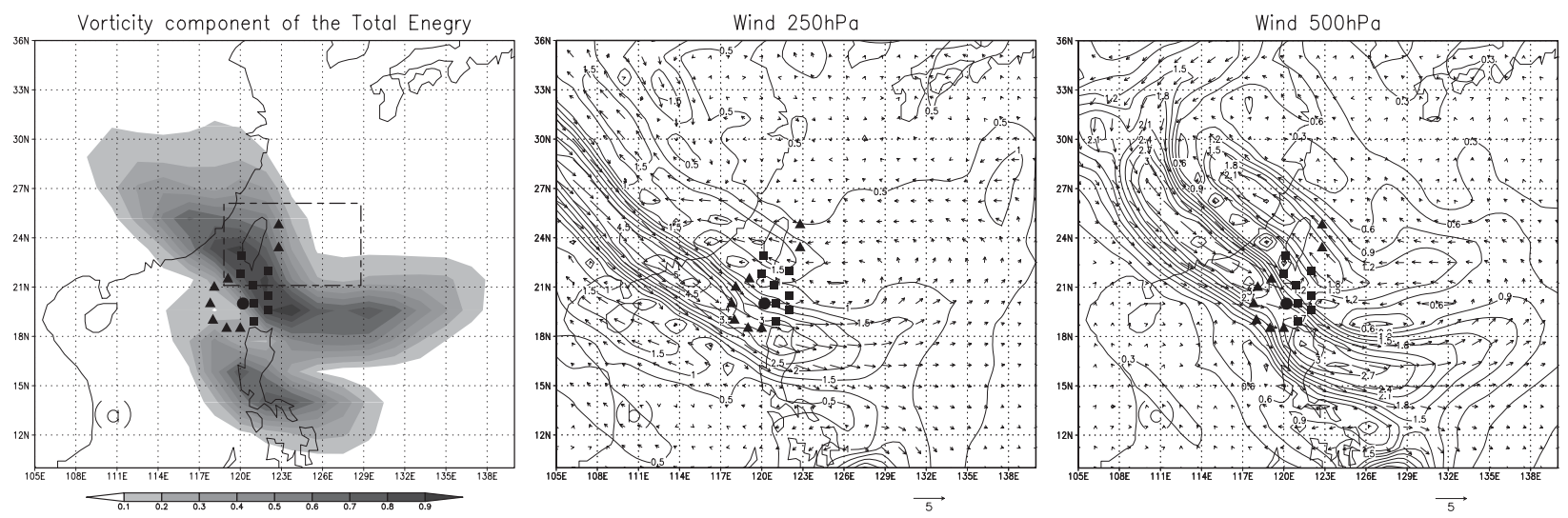

FIG. 11. (a) As in Fig. 9, but for vertically accumulated vorticity component of energy. (b),(c) The wind vectors and isotachs at $250 \mathrm{hPa}$ and $500 \mathrm{hPa}$, respectively. In (b) and (c), amplitudes are adjusted in the same way as the TEPS at JMA [vector scale (m s ${ }^{-1}$ ) at the bottom right on each figure]. The dashed rectangle in (a) shows the targeted area for the SV calculation. 

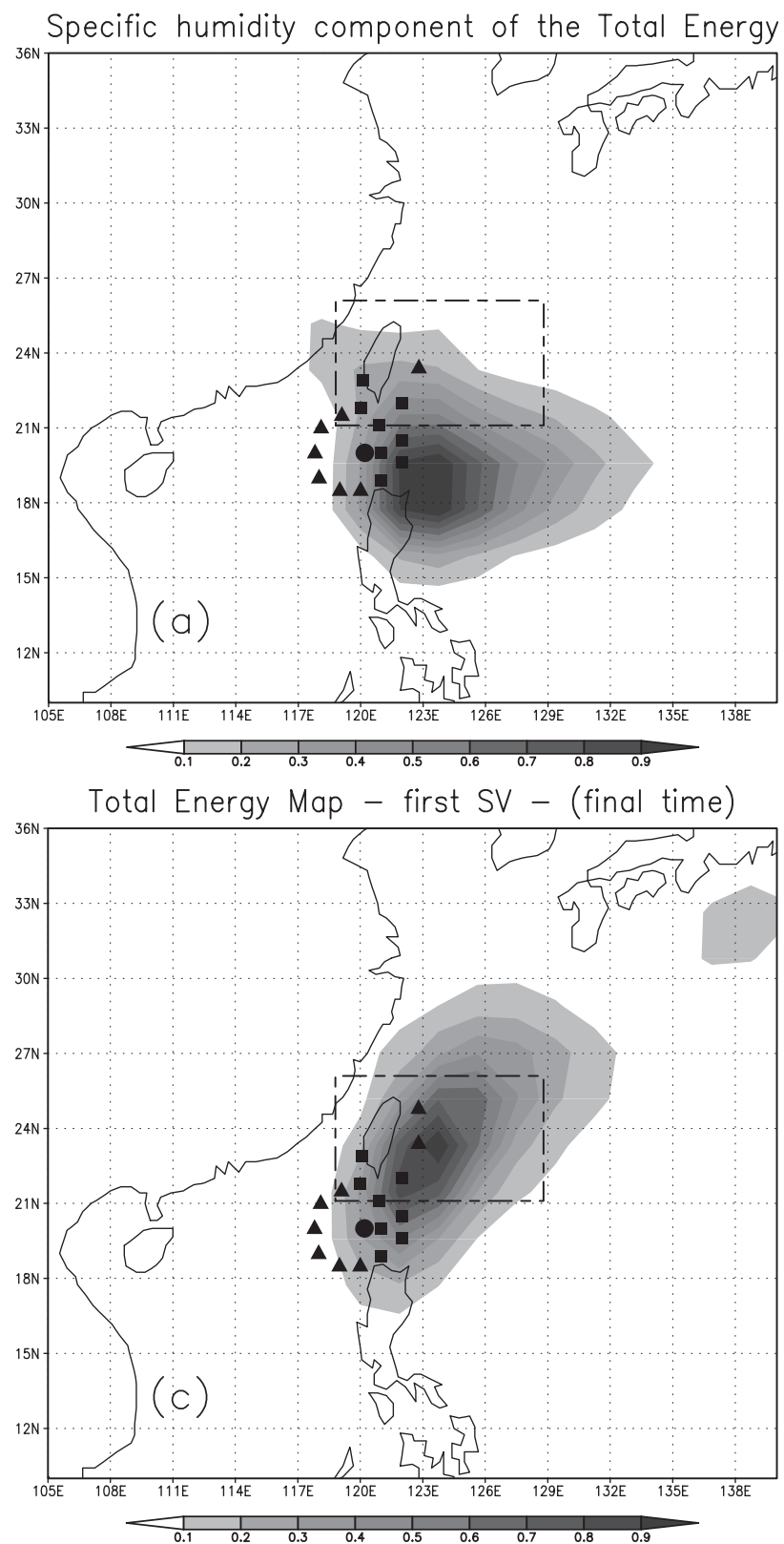

By studying the final SV, we can see a TC-like cyclonic structure whose center is close to the analyzed position of Conson at the evaluation time. In addition, Figs. 12a,b have a quite similar structure. Therefore, it can be inferred that specific humidity perturbation at around the southeastern side of Conson would also play an important role in the track forecast. In T-PARC, dropwindsonde observations were collected not only in the usual environment of the TC as has been routinely sampled by DOTSTAR but also outer regions approximately $300 \mathrm{~km}$ or more away from the TC center. These observations would help us understand through

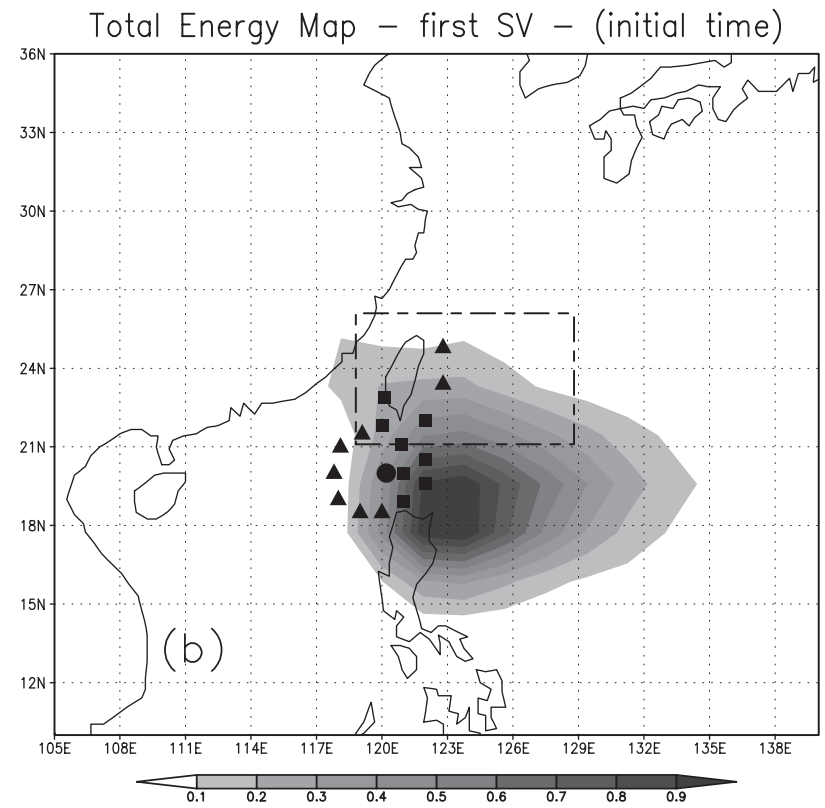

FIG. 12. (a) As in Fig. 9, but for vertically accumulated specific humidity component of energy. (b) Initial and (c) final SV calculated under the condition that only the effect of specific humidity component of energy is considered in a formulation of an initial norm. Amplitudes are normalized by the maximum value in each field. The dashed rectangle shows the targeted area for the SV calculations.

another set of OSEs how sampling convective regions related to the outer bands of TCs affects track forecasting.

Finally, to evaluate whether the SV in Fig. 9a really explains the error growth of Conson, we conduct another numerical experiment starting from an initial condition perturbed by the SV (hereafter, referred to as SVPTB). Following the same method as TEPS, the $\mathrm{SV}$ is added to the initial field in NODROP with the maximum value of the zonal or meridional wind perturbations set to $6 \mathrm{~m} \mathrm{~s}^{-1}$ and the specific humidity perturbation set to $0.8 \mathrm{~g} \mathrm{~kg}^{-1}$. The result of SVPTB is 


\section{Analysis field Wind and Geopotential Height at $500 \mathrm{hPa}$}

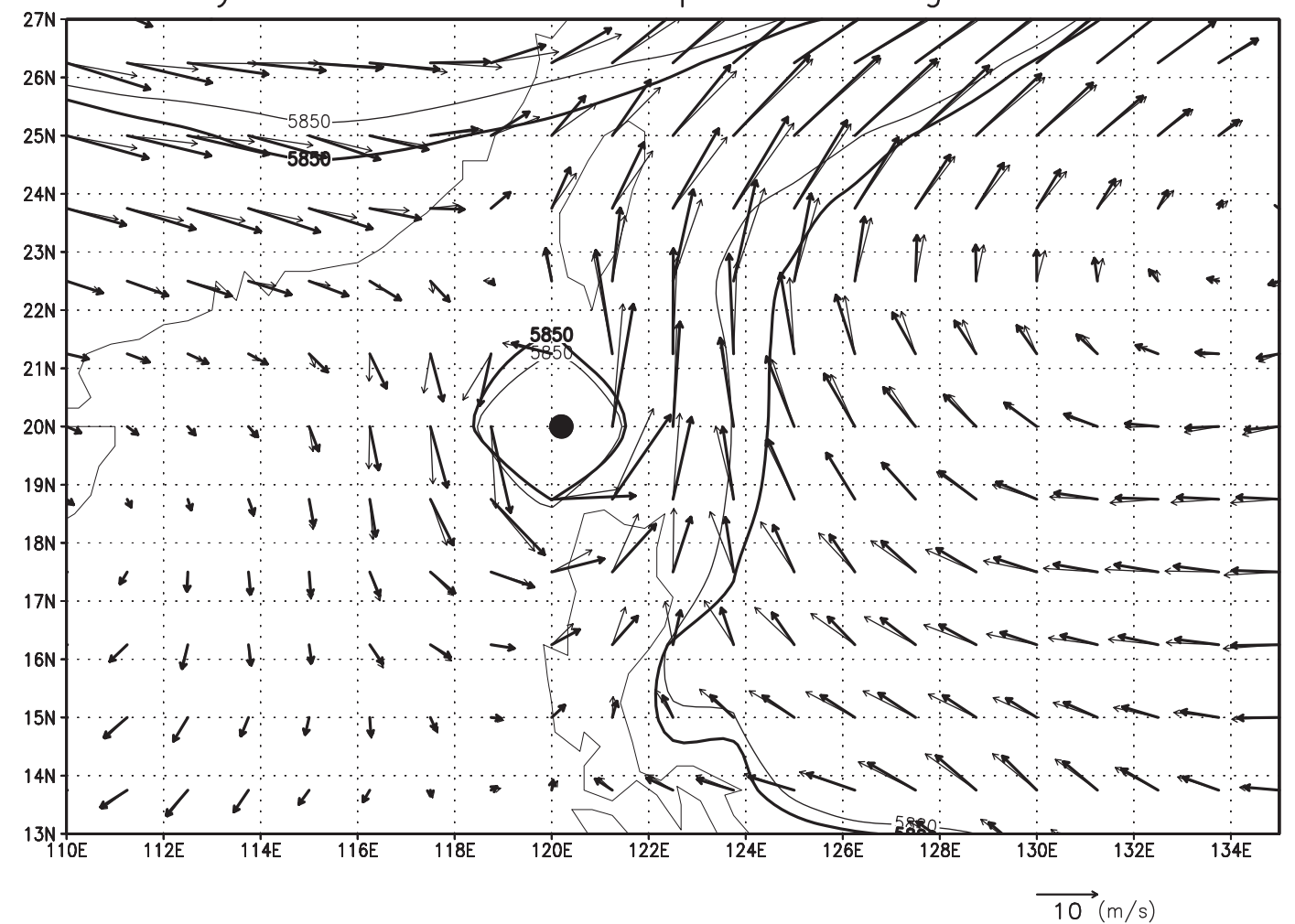

FIG. 13. Comparison of the initial fields between NODROP (thin) and SVPTB (thick) regarding wind (arrow, $\mathrm{m} \mathrm{s}^{-1}$ ) and geopotential height (line, $\mathrm{m}$ ) at $500 \mathrm{hPa}$.

shown in Fig. 4 and Table 1. SVPTB succeeds in realizing Conson's northeastward movement as in both ALLDROP and SVDROP. This result supports the theory that the SV well explains the analysis increments in ALLDROP and SVDROP.

Compared with the track forecasts in both ALLDROP and SVDROP, SVPTB considerably improves the slow and northeastward track bias. This may result from the perturbation around the westerly jet. As shown in Figs. 3a,b, Conson was located in a confluent area induced by the westerly jet and the southerly flow at the west edge of the Pacific high at 1200 UTC 8 June when DOTSTAR observations were conducted. Figure 13 shows the $500-\mathrm{hPa}$ geopotential height of SVPTB (thick) and NODROP (thin) at the initial time. Compared with NODROP, the axis of the westerly jet in SVPTB moves to the south, which may have caused more close interaction between the jet and Conson and thus have favored the northeastward movement of the typhoon. Therefore, it is proposed, if additional observations had been performed around such areas with the westerly jet as shown in the SV in Fig. 9a, the track forecast in ALLDROP and SVDROP would have had been further improved.
In all, considering that the moist SV calculated for this study has the similar structure as the analysis increments in ALLDROP and SVDROP, where Conson's track forecasts are improved, and that it has a positive impact on Conson's track forecast when it is used as an initial perturbation, we could conclude that the SV was successful in identifying a sensitive region that could potentially lead to large TC track forecast error reduction and that the JMA SV method would be useful for the sampling strategy for targeted observations in the field programs such as DOTSTAR and T-PARC.

\section{b. Implications for targeted observations}

The sensitivity analysis calculation in this study is different from that in real targeted observations as in T-PARC and DOTSTAR. We have adopted the most favorable conditions in order for the leading JMA SV to identify a sensitive region. First, the initial condition for the SV computation comes from an analysis field, not a forecast field that is necessary given the time required to notify officials about deployments. Second, there are constraints on the norm definition. Finally, the analysis TC position at the evaluation time is used to set a targeted area. The reason why we have used these conditions is 
to confirm if JMA SVs are successful in capturing a sensitive region under the easiest conditions. In that sense, this study is at a starting point to verify the feasibility of JMA SVs as sensitivity analysis guidance. Using recently collected data from T-PARC, we will further verify the effectiveness of the guidance actually used in T-PARC.

In the case of Conson, unfortunately, it seems to be quite difficult to identify the sensitive region if we used forecast data, not analysis data, as an initial condition for the SV computation because the expression of the typhoon in the forecast field is very weak. As for the actual impact of the norm constraints, removing the effect of the temperature and divergence component from the initial and final norm has little influence, but the limitation of vertical integration in the final norm changes the result. Without the limitation, the first SV is related to the development of the jet itself, not the TC. A TC-related SV as seen in Fig. 9 is calculated as the second SV. The change of a targeted area into a box with its center at a forecast position by NODROP at the evaluation time also changes the original first $S V$ to the fourth SV, the first to third SVs being related to the jet. These results imply that it is important to define a sensitive region for the TC after evaluating whether or not the final SVs are associated with the TC.

While the vorticity component of the analysis increments has the maximum value around $250 \mathrm{hPa}$ (Fig. 5), that of the first SV has a peak around $500 \mathrm{hPa}$ (Fig. 10). This difference would come from the fact that the SV does not explain the vorticity shift at $250 \mathrm{hPa}$, and that the analysis increments do not appear near the jet. However, both are successful in representing the southwesterly steering flow, which we believe should have played a critical role in improving the track forecast. As Bergot et al. (1999) and Aberson (2003) indicate, this may imply that targeted observations should be performed with a broad vertical and horizontal coverage, not only focusing on the point with the maximum sensitivity, because such flows also have a three-dimensional structure.

\section{Conclusions}

Dropwindsondes were deployed under the DOTSTAR project in an attempt to improve a track forecast of Typhoon Conson at 1200 UTC 8 June 2004. We have studied the impact of the dropwindsonde observations on the typhoon track forecast and the feasibility of adopting JMA's singular vector method as a sensitivity analysis technique. Using an operational NWP system for global forecasting at JMA, four numerical experiments, which are different in terms of the number of observations used in the 4DVAR assimilation system, are conducted. The results reveal that the observation data have a significantly positive impact on the track forecast, and that the calculated SV appears successful in representing the sensitive region that leads to large forecast error reduction.

The common features of the initial conditions that succeed in realizing Conson's northeastward movement are 1) the southwesterly steering flow from the middle to upper troposphere, associated with the west edge of the Pacific high; and 2) the enhancement of specific humidity from the southeast to the north area of Conson from the lower to middle troposphere.

Looking into the structures of the calculated SV, it turns out that the SV has the similar characteristics to the above features. In reality, when the SV is used as an initial perturbation, the perturbed run succeeds in realizing Conson's northeastward movement. The track forecast of the perturbed run had the best performance, which may indicate that the SV that was also perturbing the westerly jet favors the typhoon to move northeast. Therefore, we would presume that if additional observations had been performed around such areas as the westerly jet, the track forecast adding the data should have had much more improvement.

Our future plan is to evaluate more cases in order to obtain statistical significance and to understand the influence of targeted observations on TC forecasts. This can be achieved through the T-PARC field program conducted during the summer of 2008 and future field campaigns.

Acknowledgments. Special thanks are given to Sharan Majumdar of the University of Miami for a thorough and constructive review of the manuscript. This work was supported by Grant-in-Aid for Scientific Research (A) 19201037 in Japan. The manuscript was revised and completed under the support of Office of Naval Research Grant Number N000140810250. DOTSTAR is supported through the National Science Council of Taiwan by Grants NSC94-2119-M-002-006-AP1, NSC94-2745-P-002002, NSC95-2119-M-002-039-MY2, the Office of Naval Research Grant N00014-05-1-0672, and MOTC-CWB-96$6 \mathrm{M}-02$.

\section{REFERENCES}

Aberson, S. D., 2002: Two years of operational hurricane synoptic surveillance. Wea. Forecasting, 17, 1101-1110.

- 2003: Targeted observations to improve operational tropical cyclone forecast guidance. Mon. Wea. Rev., 131, 1613-1628.

, and J. L. Franklin, 1999: Impact of hurricane track and intensity forecasts of GPS dropwindsonde observations from the first-season flights of the NOAA Gulfstream-IV jet aircraft. Bull. Amer. Meteor. Soc., 80, 421-427. 
Barkmeijer, J., R. Buizza, T. N. Palmer, K. Puri, and J. F. Mahfouf, 2001: Tropical singular vectors computed with linearized diabatic physics. Quart. J. Roy. Meteor. Soc., 127, 685-708.

Bergot, T., G. Hello, A. Joly, and S. Malardel, 1999: Adaptive observations: A feasibility study. Mon. Wea. Rev., 127, 743-765.

Buizza, R., 1994: Sensitivity of optimal unstable structures. Quart. J. Roy. Meteor. Soc., 120, 429-451.

_ , and A. Montani, 1999: Targeting observations using singular vectors. J. Atmos. Sci., 56, 2965-2985.

Burpee, R. W., J. L. Franklin, S. J. Lord, R. E. Tuleya, and S. D. Aberson, 1996: The impact of Omega dropwindsondes on operational hurricane track forecast models. Bull. Amer. Meteor. Soc., 77, 925-933.

Chou, K.-H., and C.-C. Wu, 2008: Development of the typhoon initialization in a mesoscale model: Combination of the bogused vortex with the dropwindsonde data in DOTSTAR. Mon. Wea. Rev., 136, 865-879.

Gelaro, R., T. E. Rosmond, and R. Daley, 2002: Singular vector calculations with an analysis error variance metric. Mon. Wea. Rev., 130, 1166-1186.

Hock, T. F., and J. L. Franklin, 1999: The NCAR GPS dropwindsonde. Bull. Amer. Meteor. Soc., 80, 407-420.

JMA, 2007: Outline of the operational numerical weather prediction at the Japan Meteorological Agency. Appendix to WMO Numerical Weather Prediction Progress Rep., Japan Meteorological Agency, Tokyo, Japan, 194 pp. [Available online at http://www.jma.go.jp/jma/jma-eng/jma-center/nwp/ outline-nwp/index.htm.]

Kadowaki, T., 2005: A 4-dimensional variational assimilation system for the JMA Global Spectrum Model. CAS/JSC WGNE Res. Activ. Atmos. Oceanic Modell., 34, 1-17.

Kim, H. M., and B.-J. Jung, 2009: Influence of moist physics and norms on singular vectors for a tropical cyclone. Mon. Wea. Rev., 137, 525-543.

Komori, T., M. Yamaguchi, R. Sakai, and Y. Takeuchi, 2007: WGNE intercomparison of tropical cyclone forecasts with operational global models: Quindecennial report. Science Highlights, WCRP, 4 pp. [Available online at http://wcrp.wmo. int/documents/WGNE_TC_Intercomparison_Quindecennial_ Quicklook15Anniversary.pdf.]

Lorenz, E. N., 1965: A study of the predictability of a 28-variable atmospheric model. Tellus, 17, 321-333.

Majumdar, S. J., C. H. Bishop, B. J. Etherton, and Z. Toth, 2002: Adaptive sampling with the ensemble transform Kalman filter. Part II: Field program implementation. Mon. Wea. Rev., 130, 1356-1369.

, S. D. Aberson, C. H. Bishop, R. Buizza, M. S. Peng, and C. A. Reynolds, 2006: A comparison of adaptive observing guidance for Atlantic tropical cyclones. Mon. Wea. Rev., 134, 2354-2372.
Palmer, T. N., R. Gelaro, J. Barkmeijer, and R. Buizza, 1998: Singular vectors metrics and adaptive observations. J. Atmos. Sci., 55, 633-653.

Peng, M. S., and C. A. Reynolds, 2006: Sensitivity of tropical cyclone forecasts as revealed by singular vectors. J. Atmos. Sci., 63, 2508-2528.

Puri, K., J. Barkmeijer, and T. N. Palmer, 2001: Ensemble prediction of tropical cyclones using targeted diabatic singular vectors. Quart. J. Roy. Meteor. Soc., 127, 709-731.

Reynolds, C. A., M. S. Peng, and J.-H. Chen, 2009: Recurving tropical cyclones: Singular vector sensitivity and downstream impacts. Mon. Wea. Rev., 137, 1320-1337.

Rosmond, T. E., 1997: A technical description of the NRL adjoint model system. NRL/MR/7532/7230, $62 \mathrm{pp}$.

RSMC Tokyo-Typhoon Center, 2004: Annual report on activities of the RSMC Tokyo-Typhoon Center. RSMC TokyoTyphoon Center, 61 pp.

Strang, G., 1986: Introduction of Applied Mathematics. WellesleyCambridge Press, 758 pp.

World Climate Research Programme, 1993: Report of the eighth session of the CAS/JSC Working Group on numerical experimentation. WMO/TD Tech. Doc. 549, WMO, 41 pp.

Wu, C.-C., T.-S. Huang, W.-P. Huang, and K.-H. Chou, 2003: A new look at the binary interaction: Potential vorticity diagnosis of the unusual southward movement of Typhoon Bopha (2000) and its interaction with Typhoon Saomai (2000). Mon. Wea. Rev., 131, 1289-1300.

— _ _ - and K.-H. Chou, 2004: Potential vorticity diagnosis of the key factors affecting the motion of Typhoon Sinlaku (2002). Mon. Wea. Rev., 132, 2084-2093.

— Typhoon Surveillance near the Taiwan Region (DOTSTAR): An overview. Bull. Amer. Meteor. Soc., 86, 787-790.

—, K.-H. Chou, P.-H. Lin, S. D. Aberson, M. S. Peng, and T. Nakazawa, 2007a: The impact of dropwindsonde data on typhoon track forecasts in DOTSTAR. Wea. Forecasting, 22, 1157-1176.

— J. H. Chen, P. H. Lin, and K. H. Chou, 2007b: Targeted observations of tropical cyclone movement based on the adjointderived sensitivity steering vector. J. Atmos. Sci., 64, 2611-2626.

— , S.-G. Chen, J.-H. Chen, K.-H. Chou, and P.-H. Lin, 2009a: Interaction of Typhoon Shanshan (2006) with the midlatitude trough from both adjoint-derived sensitivity steering vector and potential vorticity perspectives. Mon. Wea. Rev., 137, 852-862.

— vation guidance for tropical cyclones in the northwestern Pacific. Mon. Wea. Rev., 137, 2471-2492.

Yamaguchi, M., R. Sakai, M. Kyoda, T. Komori, and T. Kadowaki, 2009: Typhoon ensemble prediction system developed at the Japan Meteorological Agency. Mon. Wea. Rev., 137, 2592-2604. 